\title{
Effect of Knowledge Transfer on Economic Sustainability With Network Strength as Moderating
}

\author{
Sarwoto \\ Universitas Sebelas Maret \\ Email: sarwoto220784@gmail.com
}

\begin{abstract}
This study aims to examine the effect of knowledge transfer on sustainability in the agricultural sector in Boyolali district and examine the effect of network strength as a moderating variable in the influence of knowledge transfer on economic sustainability. The data were conducted through a survey using a questionnaire with purposive sampling to 119 heads of farmer group cooperatives in Boyolali district, with a questionnaire level of 98 percent. This study applied a hierarchcal regression to test the research model used. The results show that knowledge transfer has significant influence on economic sustainability in the agricultural sector. Finding knowledge in the context of the agricultural sector in Boyolali district has a relationship that is not in line with economic sustainability. While knowledge sharing carried out positively affects on economic sustainability. The power of knowledge sharing in influencing sustainability is largely determined by the strength of the network they have.
\end{abstract}

Keywords: economic sustainability, knowledge transfer, network strength, farmer group cooperatives

\section{INTRODUCTION}

There are differences in views regarding the existence of knowledge in order to increase productivity. Taylor, who is known as the initiator of scientific management theory, argues that to increase productivity, the knowledge of each individual in the organization must be translated into standard rules (Nonaka \& Takaeuchi, 1995). These standard rules are born scientifically from the knowledge of individuals involved in the production process. Thus the role of humans in efforts to increase productivity is minimized and replaced with standardized regulations.

The view expressed by Taylor was opposed by Mayo with the theory of human relations (Nonaka \& Takaeuchi, 1995). From this view, it can stated that an increasing in productivity is influenced by social factors and interpersonal skills. This theory emphasizes on the dominant role of humans in improving productivity through continuous improvement with the optimization of their knowledge (Nonaka \& Takaeuchi, 1995). From the existing theory gap, researchers are more likely to refer to the theory of human relations in order to provide a better explanation of the effect of knowledge transfer on economic sustainability in the agricultural sector.

Knowledge transfer that occurs in organizations/companies has a direct positive influence on the performance of the organization/company (Lapre \& Van Wassenhove, 2001; Lin, 2007; Kim \& Seo, 2007). Organizational/company performance is translated into several different variables, among others: 
innovation ability (Lin, 2007) and productivity (Lapre \& Van Wassenhove, 2001; Kim \& Seo, 2007). In the context of manufacturing companies, knowledge transfer provides a large increase in company productivity (Lapre \& Van Wassenhove, 2001; Kim \& Seo, 2007). Research on the transfer of knowledge in manufacturing companies identifies that knowledge transfer is carried out through direct learning processes (Kim \& Seo, 2007) and indirectly (Lapre \& Van Wassenhove, 2001). Lin (2007) conducts research on large-scale companies defining knowledge transfer with the term sharing knowledge which is defined as social-cultural interaction, employee involvement in the exchange of knowledge, experience, and expertise through a department or organization. In his research, Lin (2007) explained knowledge sharing using 2 (two) activities, namely sharing knowledge and seeking knowledge. The results of his research show that employees who share knowledge will enhance the ability of individuals to innovate and accumulate to improve the ability to innovate the company.

Knowledge transfer can be defined as a culture of social interaction, which involves employees in exchanging knowledge, experience and expertise through all departments or organizations (Lin, 2007). Organizations are media in the implementation of knowledge transfer or knowledge sharing (Kang \& Kim, 2009). The ability to communicate with the parties involved is important to be considered in the transfer of knowledge. Good communication is when the communicator and communicant can overcome the occurrence of interference in the communication done (Rothwell, 2010). In addition, the method chosen in the transfer of knowledge must also adjust to the existing culture (Davenport \& Prusak, 2000). In this study, the transfer of knowledge into an independent variable was adopted from the transfer of knowledge used by Lin (2007) which is adapted to the context of research in the agricultural sector.

The findings of other researchers show that the transfer of knowledge that occurs in an organization/company does not directly contribute positively to the performance of the organization/company (Hansen, 1999; Tsai, 2001; Reagans \& McEvily, 2003; Sabherwal \& Sabherwal, 2005; Slaughter \& Kirsch, 2006; Rodgers \& Negash, 2007; Lee et al, 2008; Boone \& Ganeshan, 2008). In the context of a company based on the development of new products and technology, the transfer of knowledge that occurs between the units involved will slow down the innovation that will be implemented if it is not accompanied by a close bond between the units involved (Hansen, 1999; Slaughter and Kirsch, 2006; Rodgers \& Negash, 2007). The power of networks between parties involved in knowledge transfer can provide convenience in knowledge transfer (Uzzi, 1997).

In order to improve organizational performance, the implementation of knowledge transfer is important but social interaction within the organization influences the relationship between the transfer of knowledge and organizational performance (Lee et al, 2008). The quality of interaction in social networks in a community or organization has an impact on the effectiveness of the implementation of knowledge transfer. The success of knowledge transfer is largely determined by the strength of interaction between actors in a community, among them, holding roles as sources of knowledge and recipients of knowledge (Hansen, 1999; Reagans \& McEvily, 2003; Sabherwal \& Sabherwal, 2005; Uzzi, 1997; Lee et al., 2008 ) 
In accordance with the occurrence of inconsistencies in the results of research regarding the effect of knowledge transfer on performance, then in this study using the power of the network as a moderator in the influence of knowledge transfer on economic sustainability. From a series of literature reviews, research is often carried out on companies on a large scale and in the context of developed countries. Researchers still have not found research on the transfer of knowledge in the context of the agricultural sector, especially for developing countries. This makes the researcher encouraged to conduct research on the transfer of knowledge in the agricultural sector in developing countries.

Today's economic perspective, growth must pay attention to aspects of sustainability development (Jorna, 2006). Sustainable development is the basic capital to be able to do sustainability in the agricultural sector (Smith \& McDonald, 1998). There are three main components that must be considered in order to implement sustainable development, namely: ecological sustainability, sustainability of economic factors, and social sustainability which means that the development carried out can be accepted by the social environment of the community (Smith \& McDonald, 1998). From the three main components in sustainable development, the indicators that can be used to measure sustainability in the agricultural sector are biological factors, economic factors, and social factors (Smyth \& Dumanski, 1993; Smith \& McDonald, 1998). In developing countries, changes in economic and social factors are very significant as a result of environmental changes (Rao \& Rogers, 2006). From the previous description it can be concluded that the sustainability of the agricultural sector can be achieved if it meets the needs of biological environmental factors, economic factors, and social factors of society. In this study, indicators that allow us to measure sustainability in the agricultural sector are indicators of the economic aspects proposed by Smyth \& Dumanski (1993).

\section{METHOD}

This study uses primary data from respondents. The sample in this study is the Farmer Group Cooperative in Boyolali District which produces rice. The sample in this study were 119 Farmers Group Cooperatives with an acceptable level of 98.31 percent or as many as 117 Farmer Group Operations. The dependent variable in this study is economic sustainability. Measurement of sustainability variables adopts from a measure used by Smyth \& Dumanski (1993) which measures economic sustainability in which there are four indicators that measure sustainability, namely resources, economic environment, human attitudes, quality of life in terms of economics. The independent variable in this study is the transfer of knowledge which means a culture of social interaction, which involves members of the organization in the exchange of knowledge, experience, and expertise through all departments or organizations (Lin, 2007). In the transfer of knowledge, there are two activities, namely sharing knowledge and seeking knowledge. The moderating variable of this study is the strength of the network among the parties involved in the transfer of knowledge. Measurement of network strength variables adopting the measurements used by Lee et al, (2008). 
Hierarchical regression analysis is used to examine the effect of knowledge transfer on economic sustainability and then examine the effect of the interaction between the transfer of knowledge and network strength to sustainability. The hierarchical regression formula in this study is as follows:

$$
Y=\beta_{0}+\beta_{1} X_{1}+\beta_{2} X_{2}+\beta_{3} X_{3}+\beta_{4} X_{1}{ }^{*} X_{3}+\beta_{5} X_{2}{ }^{*} X_{3}+\varepsilon
$$

Explanation:

$\mathrm{Y}=$ Sustainability

$\mathrm{X}_{1}=$ Sharing knowledge

$\mathrm{X}_{2}=$ Finding Knowledge

$\mathrm{X}_{3}=$ Network Strength

$\beta 0=$ Intercept

$\beta_{1}, \beta_{2}, \beta_{3}, \beta_{4}, \beta_{5} \quad=$ The coefficient of each variable

$\varepsilon \quad=$ Random Error

The research model is presented in Figure 1.

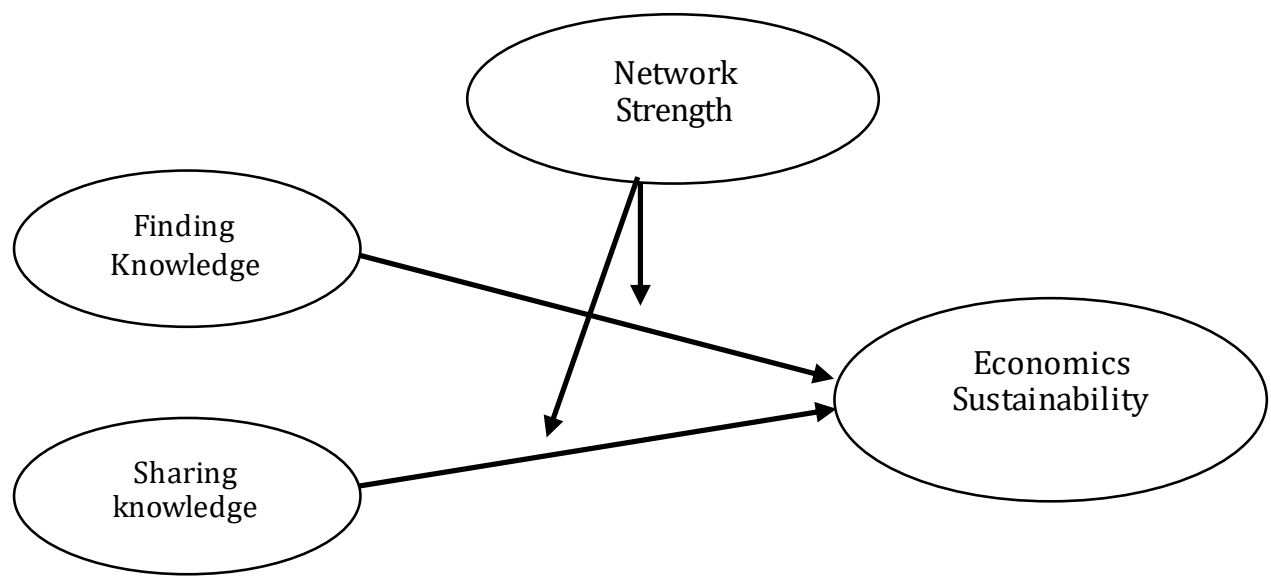

Figure 1. Research Model

\section{RESULTS \& DISCUSSION \\ Results}

The variation level of respondents in providing answers regarding variables in the study can be seen from the standard deviation values which presented in Table 1.

Table 1. Average and Standard Deviation of Respondents' Responses

\begin{tabular}{lccc}
\hline \multicolumn{1}{c}{ Variables } & Average & $\begin{array}{c}\text { Standard } \\
\text { Deviation }\end{array}$ & N \\
\hline Economics Sustainability & 2,4649 & 0,28849 & 117 \\
Finding Knowledge & 2,6185 & 0,96233 & 117 \\
Sharing Knowledge & 2,5250 & 0,44305 & 117 \\
Network Strength & 2,1750 & 0,24013 & 117 \\
\hline
\end{tabular}

Sources: Author (2018) 
Based on Table 1, the standard deviation value of the majority close to 0 (zero) indicates that the sample homogeneity is very high. This means that the variation of respondents is very low. Homogeneity that occurred in the sample of this study, one of which was caused by the similar motive for the establishment of the KKT, the similarity of the function of the establishment of KKT in Boyolali district and the condition of the geographical area that led to the similarity of the characteristics of the KKT in managing cooperatives and managing the process of agricultural production. The results of statistical testing to examine the effect of independent variables on the dependent variable in this study are presented in Table 2.

Table 2. Results of Regression Analysis

\begin{tabular}{lcc}
\hline \multirow{2}{*}{ Variables } & \multicolumn{2}{c}{ Model 1 } \\
\cline { 2 - 3 } & $\boldsymbol{\beta}$ & $\mathbf{t}$ \\
\hline Finding Knowledge & -0.307 & $-3.335^{* *}$ \\
Sharing knowledge & 0.221 & $2.294^{*}$ \\
$\mathrm{~F}(2.114)$ & $13.496^{* *}$ & \\
$R^{2}$ & 0.191 & \\
Adjusted $R^{2}$ & 0.177 & \\
\hline
\end{tabular}

Note : ${ }^{*} p<0.05,{ }^{* *} p<0.01$

Source : Author (2018)

Based on the results of statistical tests as presented in Table 2, it shows that the transfer of knowledge which consists of seeking knowledge and sharing knowledge has a significant impact on economic sustainability in the agricultural sector in Boyolali district $\left(\mathrm{F}(2.114)=13.496^{* *}\right)$. This shows that knowledge transfer has a low error rate when used to predict economic sustainability in the agricultural sector as the dependent variable. In this study shows that independent variables seeking knowledge have a negative and significant effect on economic sustainability. Statistically seeking knowledge has a coefficient of -0.307 with a significance level of 0.01 . This finding does not support the first hypothesis that seeking knowledge in the agricultural sector will positively influence economic sustainability in the agricultural sector in Boyolali district. While knowledge sharing has a coefficient of 0.221 with a significance level of 0.05 . Statistical calculations also show that the transfer of knowledge has the ability of 17.7 percent in explaining the variables of economic sustainability in the agricultural sector in Boyolali district. This finding supports the second hypothesis, namely sharing knowledge in the agricultural sector will positively affect economic sustainability in the agricultural sector in Boyolali district. Based on the results of the analysis, the researcher reconfirmed several respondents who were taken randomly through in-depth interviews. Re-interviews were conducted to obtain useful information to deepen the discussion in this study.

The results of this study do not support the first hypothesis which states that seeking knowledge in the agricultural sector will positively affect economic sustainability in the agricultural sector of Boyolali district. Although the statistical results of this study reject the proposed hypothesis, it does not mean that the results of this study can abort the existing theory regarding the transfer of 
knowledge. Based on the level of significance obtained from the results of statistical calculations, actually seeking knowledge is very good in predicting economic sustainability. The error rate is even lower than the error rate of knowledge sharing variables in predicting economic sustainability. The contextual conditions and characteristics of the study, as described above, are factors that lead to differences in the results of research with theory and with previous research that is the reference for this study. Statistically, the results of this study are not in line with the results of Lin (2007) who use the same instrument with the results that seeking knowledge has a positive effect on the ability to innovate a company in the context of large innovation-based companies. On the other hand, the findings of this study support the second hypothesis which states that knowledge sharing in the agricultural sector will have a positive effect on economic sustainability in the agricultural sector in Boyolali district. The results of this study are in line with the results of Lin's (2007) study using the same instrument. The results of statistical tests to examine the effect of independent variables and moderating variables on the dependent variable in this study are presented in Table 3.

Table 3. Results of Regression Analysis with Moderating

\begin{tabular}{lcccc}
\hline \multirow{2}{*}{ Variables } & \multicolumn{2}{c}{ Model 1 } & \multicolumn{2}{c}{ Model 2 } \\
\cline { 2 - 5 } & $\boldsymbol{\beta}$ & $\mathbf{t}$ & $\boldsymbol{\beta}$ & t \\
\hline Finding Knowledge & -0.307 & $-3.335^{* *}$ & -0.517 & -1.263 \\
Sharing knowledge & 0.221 & $2.294^{*}$ & -0.506 & $-2.313^{* *}$ \\
Finding Knowledge x Network & - & - & 0.240 & 0.642 \\
Strength & & & & \\
Sharing knowledge x Network & - & - & 0.715 & $2.751^{* *}$ \\
Strength & $13.496^{* *}$ & & $10.892^{* *}$ & \\
F (2,114); (4,112) & 0.191 & & 0.280 & \\
$R^{2}$ & 0.177 & & 0.254 & \\
Adjusted $R^{2}$ & & & & \\
\hline
\end{tabular}

Note : * $p<0.05,{ }^{* *} p<0.01$

Source: Author (2018)

Based on the results of statistical tests as presented in Table 3, after the independent variables are interacted with moderating variables, it shows that the independent variables sharing knowledge in influencing sustainability are more powerful when interacted with the power of the network. Statistically, the interaction coefficient value between the strength of the network and knowledge sharing is 0.715 with a significance level of 0.01 . Regarding the search for knowledge does not have a direct relationship with economic sustainability as the dependent variable, the strength of the network also does not moderate the influence of seeking knowledge on economic sustainability. The addition of moderating variables into the regression model increases the ability of the model to explain the variables of economic sustainability which is shown by increasing the adjusted R2 to 25.4 percent. This finding does not support the third hypothesis that the strength of the network moderates positively in the influence of seeking knowledge on economic sustainability in the agricultural sector in Boyolali district and supports the fourth hypothesis that the strength of the network moderates 
positively in the influence of knowledge sharing on economic sustainability in the agricultural sector Boyolali district.

\section{Discussion}

In the context of the agricultural sector in Boyolali Regency, the culture of kinship and mutual cooperation is still highly valued in organizational and community life. Tolerance because of having the same fate as a very solid capital base in many ways, including in sharing knowledge. With the existence of this capital, it causes the creation of close relations between the actors of the agricultural sector and the ease in equating perceptions related to the agricultural business being carried out. The ease of equality of perception is acknowledged to make it easier for agricultural sector actors who are members of the KKT to share knowledge. This is in line with the opinion of Davenport \& Prusak (2000); Rothwell (2010). The KKT organizes meetings with members on a regular basis based on the agreement of members and incidental meetings when there is new knowledge provided by the relevant agency through the KKT Chairperson. Through these meetings knowledge sharing activities take place. In connection with the form of a community system that is community-based and has a majority job as a farmer, the knowledge sharing activity is almost unlimited in routine meetings. Knowledge sharing activities also take place in daily life or during breaks when doing agricultural land work activities.

The frequency level of knowledge sharing provides additional knowledge for KKT members. The acquired knowledge is a basic capital to achieve economic sustainability in the agricultural sector in Boyolali district. This is in line with the opinions of Nonaka \& Takaeuchi (1995), Prusak \& Davenport (2000). The results of this study explain that the strength of the network positively moderates the influence of seeking knowledge on economic sustainability in the agricultural sector of Boyolali district. This is the impact of the absence of knowledge seeking activities among the actors in the agricultural sector in Boyolali district. Therefore, seeking knowledge does not have a positive effect on economic sustainability and the strength of the network also does not moderate the influence of seeking knowledge on economic sustainability. While knowledge sharing can better explain economic sustainability when interacted with network strength. Network strength has a large role in the influence of sharing knowledge on economic sustainability. This means that the strong weak influence of knowledge sharing on economic sustainability is largely determined by the strength of the network owned by agricultural sector actors in Boyolali district. In the context of the agricultural sector in Boyolali Regency, the effectiveness of knowledge sharing is largely determined by the strength of the network owned by agricultural sector actors both internally and externally. The stronger the power of the network owned by the agricultural sector actors in Boyolali Regency, the agricultural sector in Boyolali regency increasingly has a high level of economic sustainability. The weaker the strength of the network owned by the actors of the agricultural sector in Boyolali Regency, the lower the level of economic sustainability. This finding is in line with research conducted by Lee et al. (2008). In general, statistical analysis using regression produces significant constants and coefficients. This means that 
the regression model can be used to predict economic sustainability in the agricultural sector in Boyolali district. Significant constant values indicate that there are other factors outside the model that can affect sustainability.

\section{CONCLUSION}

In the context of the agricultural sector in Boyolali district with a sample of the Farmer Group Cooperative, it turns out that seeking knowledge has no positive effect on economic sustainability. Although significant, the relationship between the two is not in the same direction. While knowledge sharing has a significant positive influence on economic sustainability. The strength of the network moderates the influence of knowledge sharing on economic sustainability. The conclusions of the results of the research are Knowledge Transfer influencing economic sustainability and Network Strength moderating the influence of knowledge transfer on economic sustainability which can provide empirical evidence that knowledge transfer can better explain economic sustainability if interacted with network strength. This means that the effectiveness of knowledge transfer in influencing economic sustainability is determined by the strength of the network. Transfer of knowledge without being based on strong network strength, it will have a weak influence on economic sustainability. Conversely, if the transfer of knowledge is accompanied by strong network strength, it will be better to influence economic sustainability. Future research should be conducted on large samples and carried out longitudinally by measuring economic sustainability from various perspectives. Research can be conducted in a wider area that make the results can be used for generalization. In addition, additional independent variables are also needed by adjusting the research context to better explain economic sustainability. From a practical perspective, the relationship between knowledge sharing, network strength, and economic sustainability can provide clues on how interested parties can develop knowledge-based cultures to achieve and enhance the sustainability of their businesses.

\section{REFERENCES}

Boone, T., \& Ganeshan, R. 2008. Knowledge Acquisition and Transfer Among Engineers: Effects of Network Structure. Managerial and Decision Economics, 29, 459-468

Davenport, T. H. \& Prusak, L. 2000. Working Knowledge: How Organizations Manage What They Know. Havard Business School Press: Boston Massachusetts.

Hansen, M.T. 1999. The Search-Transfer Problem: The Role of Weak Ties in Sharing Knowledge Across Organization Subunits. Administrative Science Quarterly, 44(1), 82-111

Jorna, R. 2006. Sustainable Innovation. Greenleaf Publishing Ltd: United Kingdom.

Kang, M., \& Young, G. 2009. A Multilevel View on Interpersonal Knowledge Transfer. Journal of the American Society for Information Science and Technology, 61(3), 483-494. 
Kim, I., \& Hae, L. S. 2007. Depreciation and Transfer of Knowledge: an Empirical Exploration of a Shipbuilding Process. International Journal of Production Research, 47(7), 1857-1876.

Lapre, M. A., \& Luk, N. V. W. 2001. Creating and Transferring Knowledge for Productivity Improvement in Factories. Management Science, 47(10).

Lee, R. P., Daekwan, K. O. C., \& Jean L. J. 2008. Knowledge Transfer Between Multinational Corporations' Headquarters and Their Subsidiaries : Influences on and Implications for New Product Outcomes. Journal of International Marketing, 16(2).

Lin, H. F. 2007. Knowledge Sharing and Firm Innovation Capability : an Empirical Study. International Journal of Manpower, 28(3/4), 315-332

Nonaka, I., Takaeuchi, H. 1995. The Knowledge-Creating Company. Oxford University Press: New York

Rao, N. H., \& Rogers, P.P. 2006. Assessment of Agricultural Sustainability. Current Science, 91(4).

Reagans, R., \& Bill, M. 2003. Network Structure and Knowledge Transfer: The Effects of Cohesion and Range. Administrative Science Quarterly, 48(2), 240-267.

Rodgers, W., \& Solomon, N. 2007. The Effects of Web-Based Technologies on Knowledge Transfer. Communications of The Acm. July 2007/vol. 50, no. 7

Rothwell, J. D. 2010. In the Company of Others : an Introduction to Communication. 3rd Edition, New York, NY; Oxford University Press, 11-15

Sabherwal, R., \& Sanjiv, S. 2005. Knowledge Management Using Information Technology: Determinants of Short-Term Impact on Firm Value. Decision Sciences, 36(4), 531-567.

Slaughter, S. A., \& Laurie J. K. 2006. The Effectiveness of Knowledge Transfer Portfolios in Software Process Improvement: A Field Study. Information Systems Research,17(3), 301-320.

Smyth, A. J., \& Dumanski, J. 1993. FESLM: an international framework for evaluating sustainable land management. World Soil Resources Report No. 73. Rome: FAO.

Smith, C. S., \& McDonald, G. T. 1998. Assessing the Sustainability of Agriculture at the Planning Stage. Journal of Environmental Management, 52, 15-37

Tsai, W. 2001. Knowledge Transfer in Intraorganizational Networks: Effects of Network Position and Absorptive Capacity on Business unit Innovation and Performance. Academy of Management Journal, 44(5), 996-1004.

Uzzi, B. 1997. Social Structure and Competition in Interfirm Networks: The Paradox of Embeddedness. Administrative Science Quarterly, 42(1), 35-67. 